\title{
O “DISCURSO QUEBRADO” DE SERGE DOUBROVSKY: ESCRITURA COMO INSTALAÇÃO?
}

Luciana Persice Nogueira

(UERJ)

\section{RESUMO}

A aproximação do romance de Serge Doubrovsky da ideia de instalação é possível a partir da proposta geral do autor (explicitada em vários de seus ensaios) ao elaborar sua "autoficção": ele visa solicitar a sensibilidade do leitor por vias que ultrapassam a mera leitura culta. Ele busca, através de sua "escritura consonântica", um contato direto com outras artes, notadamente a música e as artes visuais, pois a calca em propriedades fonéticas que, segundo ele, geram criatividade e produtividade no campo semântico. Além disso, o autor pretende realizar uma comunicação direta com a afetividade e os impulsos afetivos de seu leitor através da sua "psicanálise existencial" e de sua escritura "para o inconsciente". O "discurso quebrado" é seu principal instrumento para atingir esse objetivo. Essa proposta, aparentemente inovadora, pode ser rastreada em um de seus temas de estudo preferidos: a obra de Marcel Proust.

PALAVRAS-CHAVE: Doubrovsky, autoficção, discurso quebrado, Proust

Serge Doubrovsky (1928) é professor, ensaísta, crítico e teórico da literatura, romancista e também tradutor (para o francês) de títulos de Truman Capote. Especialista em literatura francesa - e no seu ensino -, particularmente o classicismo francês, começou sua carreira literária escrevendo contos e um romance curto, editados no mesmo tomo, Le Jour $S$ (1963). Seu primeiro romance de maior envergadura, La Dispersion (1969), já é autobiográfico, mas ainda não integra aquilo que o tornará célebre nos meios acadêmicos e literários: sua obra "autoficcional".

A partir de 1970, Doubrovsky se dedica à escritura de um romance de proporções proustianas e inspiração psicanalítica: mais de três mil páginas 
escritas num fluxo ininterrupto de efeitos sonoros e gráficos, calcado em associações de ideias, sons e citações, pelo viés da exploração do inconsciente: Le Monstre (que permanecerá como manuscrito até que uma equipe de pesquisadores geneticistas passou a trabalhar com o autor e conseguiu empreender sua publicação em 2014). Em uma das notas a esse texto, a ambição de seguir os passos de Marcel Proust não deixa margem para dúvidas: "Único livro. Verdadeiro. O livro proustiano. Vou re-escrever. Em Busca do Tempo Perdido. Minha busca. Já escrito" (apud GRELL s/p; essa e as demais traduções livres são minhas).

Anos depois, porém, o autor abandona seu projeto de "re-escritura", e o substitui por outro: escrever um romance - e não uma autobiografia - em que o nome do personagem coincida com o nome do autor (desafio lançado pela coluna lacunar na grade tipológica de Philippe Lejeune em seu estudo sobre a autobiografia, Le Pacte autobiographique, 1975). Sua busca passa a ser a de um romance "ainda não escrito", dentro de um gênero, até então, inexistente (embora exemplos pontuais de romances que ultrapassem os limites do gênero possam ser elencados).

O primeiro romance que Doubrovsky escreve segundo essa fórmula deliberada e autoimposta é composto a partir do remanejamento parcial do manuscrito de Le Monstre, reduzido a 450 páginas sob o título de Fils (1977). ${ }^{1}$ E é na contracapa desse romance que o autor cunha o seu neologismo, definindo-o para o seu leitor:

Autobiografia? Não. Esse é um privilégio reservado aos grandes desse mundo, no crepúsculo da vida, e num belo estilo. Ficção, de eventos e de fatos estritamente reais, por assim dizer, autoficção, por se haver confiado a linguagem de uma aventura à aventura da linguagem, fora dos limites da sensatez/sabedoria [sagesse] e da sintaxe do romance, tradicional ou novo. Encontros, fios/filiações [fils] de aliterações, assonâncias, dissonâncias, escritura de pré ou pós-literatura, concreta, como se diz da música. Ou então, autofricção (DOUBROVSKY 1977, s/p; o itálico das citações, exclusive os termos em francês entre colchetes, são do texto).

Primeiramente, Doubrovsky explica ao leitor sua intenção, decodifica sua estratégia e revela que seu livro deve ser lido comme il faut: um exercício lúdico onde estão semeados fios/filiações de sentidos por meio de fios/filiações de efeitos sonoros e gráficos do texto.

Em seguida, nessa explicação da regra do jogo escritural, o autor enfatiza a ideia de fazer do uso da linguagem uma aventura - em clara referência a Jean Ricardou e à sua "aventura de uma escritura / escritura de uma aven- 
tura" ao falar do romance (em Pour une théorie du Nouveau roman, 1971). A autoficção apresenta-se, portanto, também, como uma elaboração fundamentalmente intertextual e metatextual, e as remissões a outros textos (ficcionais ou ensaísticos) passam a integrar a estratégia da escritura, assim como deverá constituir um dos motores da leitura.

Assim, ao menos em parte, a leitura comme il faut do texto implica em solicitar a enciclopédia de conhecimentos do leitor. Mais que isso: para que o jogo se faça, o leitor deve estar atento para o fato de que texto rompe com o senso comum e com a sintaxe habitual, buscando, não "tempos perdidos" (como Proust), mas tempos, compassos, ritmos, sonoridades e evocações "encontráveis", potenciais, possíveis, virtuais, inusitados, surpreendentes, no contato entre o texto, sua musicalidade e sua materialidade ("autofricção") em um nível mais evidente ou explícito do que é dito.

Essa aventura é, porém, "contraditória" e "estranha", pois trata-se da empreitada de um "sujeito (pessoal) de se buscar [récupérer], em sua essência, através de uma linguagem (forçosamente impessoal)" (idem, p.51). Esse hiato compõe o espaço onde opera o que Doubrovsky denomina, em sua primeira autocrítica a Fils de "escritura consonântica": no artigo "L'initiative aux maux: écrire sa psychanalyse" (literalmente: "a iniciativa dos males, escrever a própria psicanálise", 1980, em jogo fonético com a "initiative aux mots" - a iniciativa das palavras, preconizada por Mallarmé (em "Quant au livre", in Divagations, 1897), o autor avisa que não faz uma "escritura do inconsciente", mas uma "escritura consonântica" (DOUBROVSKY 1980, p.194) elaborada sobre propriedades fonéticas, onde homofonias, aliterações e assonâncias geram criatividade e produtividade no campo semântico. É como se as propriedades fonéticas induzissem, por contágio, à própria geração dos campos semânticos. E esse processo criativo, segundo ele, é o resultado de um

[...] desejo vivo intenso, constante (...) recompensado por um prazer muito intenso quando ocorria uma descoberta imprevista (...) uma escritura fundada em jogos de som e de sentido depende inteiramente do caráter aleatório dos encontros linguìsticos. Ressalto o afeto [no sentido psicanalítico] do escritor, provocando, em troca, uma forte reação afetiva no leitor. (idem, p.181)

O autor ambiciona, portanto, uma comunicação direta com a afetividade e os impulsos afetivos de seu leitor, não restringindo sua escritura a um jogo intelectual ou cerebral, visando uma leitura culta. A propósito de seu 
próprio desejo, do motor de sua escritura (aspecto que costuma analisar nos escritores que estuda e analisa, enquanto crítico), revela a importância do prazer diante das descobertas fortuitas de duplicidades e ambiguidades no jogo entre sentido e som, na "lógica da consonância" (p.191).

\section{A escritura consonântica}

O jogo de encontros lingüísticos pode ser aleatório, mas a preocupação em produzi-lo impõe à linguagem um sistema de cauções que condicionam a liberação de sentidos. Daí sua crítica à noção de gratuidade dos jogos de palavra desenvolvido em $O$ s Chistes e sua relação com o inconsciente, onde Freud advoga que a criança experimenta, de maneira "selvagem", arbitrária, não-tendenciosa, as variações e progressões na consonância, por meio de jogos linguísticos que não levam em conta os sentidos produzidos. Doubrovsky recusa o caráter leviano do jogo de palavra, introduz-lhes o elemento inconsciente que "atravessa integralmente o sujeito e sua linguagem" (p.182) e afirma que o prazer que lhe é decorrente está na "transgressão" em que implica o "prazer consonântico" (p.183).

Sempre segundo Doubrovsky, a presença do inconsciente e do prazer da transgressão subverte a ordem estabelecida da linguagem, racional, o Logos parental (ibid) e libera a afetividade contida no prazer do jogo. As operações de linguagem suscitam a afetividade do "afrontamento angustiado ou jubilativo diante dos efeitos de presença ou ausência" do jogo Fort/Da de que fala Freud, e que Doubrovsky afirma estar calcado na nostalgia (sorte de afetividade) implicada na "iniciativa das palavras".

Nessa medida, pode-se aproximar o intento de Serge Doubrovsky, ao realizar sua escritura consonântica (à base da autoficção), como uma transplantação, para o ambiente da perigrafia do livro, dos princípios da instalação nas artes. Pois parece ser amplamente aceito que a instalação (que se generalizou à mesma época em que Doubrovsky elaborou o seu gênero original) designa uma forma de expressão artística (que abarca as artes plásticas, o cinema, a fotografia e manifestações performativas), em que as dimensões espacial e temporal das obras são levadas em conta. Inclui-se, na sua característica estética, o próprio espaço para o qual elas foram criadas, assim como a interação temporal (mais ou menos efêmera, dependendo do caso) entre o observador e a obra. Ela pode provocar sensações (auditivas, táteis...), pois interage com o corpo e o ponto de vista do observador. No conceito de obra/instalação, incluem-se, também, a interação e os efeitos que ela permite, sugere e provoca - instala, instila e instiga, diria ele? 
Assim é, também, segundo Serge Doubrovsky, a escritura consonântica e autoficcional: para além da estética da recepção, ela joga com um princípio lúdico, que se fundamenta em experiências que ultrapassam os limites da página escrita; trata-se de um apelo à musicalidade (pela fonética) e às artes visuais (pelos efeitos gráficos) que, ao serem socilitadas, acionam reações de ordem estritamente subjetiva e pessoal. A leitura do texto é uma travessia (uma "aventura", diz ele, em eco a Ricardou) entre formas e sentidos.

A musicalidade e a materialidade do texto são manipuladas com o objetivo de ir um passo além do preconizado por Mallarmé: ao falar da "initiative aux mots", o poeta (além de professor, crítico, teórico e tradutor, como Doubrovsky) refere-se à subtração da presença do poeta da linguagem de sua obra (que também constitui uma das características da instalação). Doubrovsky, ao deformar a citação (mots/maux), coloca, no lugar da destronada iniciativa do autor, a iniciativa do inconsciente: "escritura para o inconsciente" (p.195), que pretende reproduzir os seus efeitos no âmbito da linguagem, entabulando o que acredita ser uma comunicação "direta de insconsciente a inconsciente" (p.197) entre autor e leitor (diferente de uma "escritura do inconsciente", de tipo automático, ou "sobre o inconsciente", de algumas abordagens psicanalíticas).

Um exemplo desse texto lúdico e empático pode ser identificado nas primeiras linhas do segundo romance autoficcional do autor:

\title{
BROUHAHA
}

\author{
dans la cohue je m'avance invités agglutinés en \\ groupes gesticulants assourdi du vacarme des voix des verres \\ - Oui, elle voudrait faire votre connaissance. Elle me l'a demandé. \\ - C'est vrai? \\ - Absolument. Venez, je vais vous présenter.
}

raout universitaire foule des collègues sée de tintements au bout des doigts agités au passage roucoulent ricanent rauques jappements des gosiers savants avinés (DOUBROVSKY 1990, p.11). ${ }^{2}$

Essas variações gráficas de que se serve Doubrovsky em sua escrita 
- itálicos, maiúsculas, espaços irregulares entre palavras (e entre os "parágrafos" ou partes do texto) - agem no sentido de dar uma oralidade ao texto, realizando o que Barthes idealizara em O Prazer do texto: "Se fosse possível imaginar uma estética do prazer textual, teríamos nela: a escrita em voz alta." (BARTHES 1983, p.115; primeira edição na França em 1973).

O texto de Serge Doubrovsky está repleto de vazios e assimetrias no transcorrer das linhas: ele é poroso, quebradiço, esfacelado. Evolui na irregularidade lacunar de seu caráter telegráfico, e instaura uma lógica descontínua, imprevisível, que dificulta o fluxo da leitura, tornando-a tensa e alerta às supressões de pontuação e articuladores, tendo por balizas apenas a formação de parágrafos (às vezes, aparentemente desconexos ou aleatórios) e a divisão em capítulos. É como se o autor transcrevesse, de fato, um discurso oral: as alterações gráficas chamam atenção para as conexões implícitas entre os segmentos textuais, convidando a um mergulho empático no que (não) é dito.

$\mathrm{O}$ trecho citado acima não foi escolhido ao acaso. Trata-se do incipit de um livro elaborado como hipertexto da obra proustiana: Un Amour de soi (1982, 1990 e 2001). Livro particularmente importante dentro do projeto escritural do autor que, a certa altura, pretendeu "re-escrever" a Recherche. O primeiro romance autoficcional, Fils, teve por hipotexto a obra de Racine; agora, Doubrovsky retoma uma obsessão antiga, primeva, que ocupa boa parte de sua obra ensaística enquanto avança na série romanesca (La Place de la madeleine, écriture et fantasme chez Proust, escrito em 1974, livro dedicado ao estudo da Recherche onde o autor trata o episódio da madeleine como "matriz narrativa" e "metáfora ideal" edipiana; "Faire catleya" (1979), pós-escrito a La Place, sobre o eufemismo de Swann; e "Corps du texte / texte du corps", artigo incorporado a Autobiographiques: de Corneille à Sartre (1988, mas publicado primeiramente numa revista de estudos proustianos, em 1987), sobre o tema da viagem, o movimento da memória e o mito do nascimento do livro, impulsionados pelo incipit de Du Côté de chez Swann).

A importância do incipit proustiano nos estudos do crítico Doubrovsky é transplantada para a sua própria produção ficcional, e as primeiras linhas de Un Amour de soi, como se viu, vão instaurar uma estrutura dialógica (o "eu" e o "outro") em meio ao tumulto de seres e vozes (antípoda do incipit proustiano, do homem que lê e reflete em seu leito, à espera do sono, num jogo de palavras que não feito explicitamente por Proust, "il lit dans son lit", deixado em suspenso, sugerido, como tantos outros, ao longo dos tomos) - que constitui o esteio da trama do homem que narra "o amor de si".

Em Fils, o autor decodificara seu intento na contracapa; em Un Amour 
de soi, há uma primeira página, não numerada, que ele assina e onde apresenta seu romance, deixando claro o itinerário da leitura e da compreensão da trama: "estranha aventura" de um professor que ministra aulas sobre Proust e que descobre, um dia, "ser" Swann, ao se apaixonar por "uma mulher que não faz o seu gênero" mas que, diferentemente de Swann, resolve escrever sobre esse amor, passar a vida a limpo, "se escrever". Em novo esclarecimento sobre a autoficção, ele afirma que somente ela "assume realmente (...) o fardo das verdades penosas": o narrador, sendo si mesmo, mas também outros, divide com o autor e o personagem o peso do que é dito (DOUBROVSKY 1990, s/p).

Segue, então, o incipit de Un Amour de soi (de agora em diante, $A S$ nas citações) e sua estrutura dialógica e, portanto, dicotômica estabelecendo uma mise en abyme das dualidades que vão permear toda a obra: Serge e Rachel, interior e exterior, consciente e inconsciente, indivíduo e sociedade, Paris e Nova York, francês e inglês, professor e escritor, mestre e aprendiz, esposa e amante, saber e desconhecer, entre outras.

Mais precisamente, trata-se de um diálogo entre dois sobre um terceiro - um outro, o que anuncia tanto o face a face autoficcional (encenação textual e discursiva do exercício narcísico de um autor em frente ao espelho), quanto a temática do outro: o duplo que se desconhece e idealiza.

Dicotomia e dualidade, marcas da estrutura especular de Un Amour de soi, condensadas no desdobramento: "je m'avance", que ilustra alguém empurrando a si mesmo em meio ao tumulto de sons e seres como se ele próprio fosse "um outro". E o termo "brouhaha", mumúrio, acaba revelando-se uma mise en abyme dupla, pois instaura o incipit ao mesmo tempo em que é uma onomatopéia (mimologia, palavra cuja pronúncia imita, circularmente, o som daquilo que significa), espécie de espelhamento entre som e sentido, coadunado com as explanações de Doubrovsky sobre a escritura consonântica.

É possivel que o incipit de Un Amour de soi seja, mais uma vez, uma citação de O Prazer do texto:

[...] eu tentava, por brincadeira, enumerar todas as linguagens que entravam na minha escuta: músicas, conversas, ruídos de cadeiras, de copos, toda uma estereofonia (...) Tudo isso também falava em mim (...) e essa fala dita 'interior' assemelhava-se muito ao barulho do lugar (...) as palavras, os pequenos sintagmas, os fins de fórmulas passavam por mim, e não se formava nenhuma frase, como se fosse essa a lei desta linguagem. (BARTHES 1983, p.93-94) 
Esse trecho contém algumas das principais características do texto de Serge Doubrovsky: a "brincadeira"-jogo, a "diversidade de linguagens" (que podem ser as linguagens provenientes de outros textos - as citações), a música (presente no romance através do esforço consonântico e nos nomes de alguns capítulos: "Prélude", "Fugue", "Coda"), a "fala interior" da autoficção, e a "não-frase" que é "a lei desta linguagem" e que constitui o estilo fragmentário do autor. Quanto ao resto da "esterofonia", ela está marcadamente presente em todo o prólogo, que antecipa o encontro dos protagonistas na confusão sonora de um bar, na sucessão de termos e expressões: cohue, assourdi du vacarme des voix des verres, tintements, souffle des rires, trillent, roucoulent, ricanent, rauques jappements (do incipit já citado), além de "salon tourbillonnant d'échos, tohu-bohu cravaté tintamarre disert d'érudition (...) à peine entré elle me saisit m'entraîne à corps et à cris dans la mêlée", por exemplo $\left(A S\right.$, p.12). ${ }^{3}$

Os exemplos do trabalho com a sonoridade das palavras e com os efeitos sonoros entre os segmentos textuais se estenderia, praticamente, à totalidade do romance, numa espécie de "esterofonia" compulsiva, transgressiva, tornada norma da autoficção.

\section{0 "discurso quebrado"}

É também na apresentação de Un Amour de soi que o escritor cunha un novo conceito relativo à autoficção: "Em nosso fim de século, as elegâncias refinadas dos anos de Swann desapareceram: bate-se no peito em mea culpa, raivosamente (...) Hoje, o enfrentamente de um homem e uma mulher (...) não é mais a voluptuosa invenção do Outro (...)”. De antemão, é explicitada a diferença entre os fins de século, o de Proust e o atual. E a linguagem que vai expressar essa diferença é definida como "discurso quebrado":

A arte do não-amar exige sua linguagem crua e cruel. Civilização decomposta, discurso quebrado (...) cedendo a iniciativa ao jogo inopinado das palavras, às derrapagens dos sons e dos sentidos, a infelicidade de viver se transmuta pouco a pouco em alegria de escrever. Essa história trágica, assim distanciada, se torna uma história engraçada.

Mais uma vez, Mallarmé é invocado: "ceder a iniciativa ao jogo inopinado das palavras": poética do discurso do romance de hoje; reflexo de uma era decomposta, "desconstruída"; mimetismo estrutural, qualidade camaleônica de um autor que busca a expressão de um tempo desavido; ou jogo de espelhismos, que tece a trama e a textura - esfrangalhada - da escritura. Texto 
partido, partitura do texto: na busca da identidade com Swann ou Proust, destaca-se a discrepância, o desconcerto, a dissonância: linhas cortadas que pautam a história narrada, onde embrenham-se autor, narrador e protagonista, engajado(s) na representação da harmonia perdida.

Há, aqui, dois aspectos a serem considerados: o elemento histórico ("civilização decomposta") e a formalização do "discurso quebrado".

Antes de mais nada, é preciso situar a elaboração da autoficção como consequência inevitável do posicionamento de Doubrovsky enquanto crítico: desde seu primeiro livro de ensaios, ele privilegia o que denomina de "psicanálise existencial", que define como tributária de um amálgama de trabalhos de Sartre, Merleau-Ponty, Marx, Freud e Hegel (DOUBROVSKY 1963, p.20; sua orientação intelectual inicial tendo sido o existencialismo de tipo sartriano). Nessa psicanálise existencial, o crítico privilegia o homem enquanto ser definido histórica e culturalmente. Importa-lhe, porém, a existência imaginária do homem, não sua biografia; e, sobremaneira, o resultado de sua linguagem, que alinhava, na obra, o seu universo imaginário numa infinitude de significações (1966, passim).

Mais pontualmente, nessa obra, Doubrovsky destaca o que a põe em movimento, gera sua escritura, e anima o desejo de dar-lhe forma. Essa será uma tônica de seu trabalho crítico, ao ponto de insistir sobre ela quinze anos depois, noutro ensaio:

Interessa-me, na perspectiva desse estudo (qual é o poder gerador da linguagem? Que dinamismo lança e propulsiona um texto?), o que, dentre as virtualidades significantes da língua, solicita, retém, cativa a atenção, ou melhor dizendo, o desejo do escritor. (DOUBROVSKY 1988, p.51-52)

$\mathrm{O}$ autor é um homem definido, assim, por sua linguagem: homem disseminado pelo texto através de suas tautologias e composições semânticas. Por isso, Doubrovsky faz elaboradas análises de texto, examinando detalhadamente o uso das repetições como reveladoras de matrizes textuais. Esse é o eixo de seu estudo do incipit proustiano, por exemplo (de maneira muito sucinta, apenas para ilustrar como esse interesse se expressa na prática da análise crítica, pode-se dizer que Doubrovsky vê, no prólogo da Recherche, o padrão circular da obra, a partir do que batiza de "escritura da insistência"; idem, p.54: a repetição do tema da viagem e dos termos ligados a ele - viajante, estação de trem, viajar, retorno, re-encontro, ida-e-vinda, percurso circular difuso e fugidio, entre tantos outros - garantiria "justamente o domínio da circularidade, desposando o seu movimento: Com- 
bray, Balbec, Paris, Doncières, Veneza”, alargando os círculos, que Proust teria fixado ao redor de seu narrador, leitor menino: "Um homem que dorme mantém ao seu redor o fio das horas, a ordem dos anos e dos mundos", diz Proust; para seu crítico, o movimento espiral, e o retorno da obra sobre si mesma, é conseqüência da forma espiral inscrita já em suas primeiras linhas.

É a identificação desse desejo que leva Doubrovsky a inserir o inconsciente na sua psicanálise existencial:

Durante muito tempo, tive tendência a dar conta desse movimento da existência através das categorias gerais do estar-no-mundo, das estruturas "existenciais" que a filosofia de mesmo havia, paulatinamente, identificado. Devido ao meu caminho pessoal, fui levado a acrescentar outro funcionamento, sutil, sorrateiro, da obra: o do inconsciente. (Idem, p.6)

Os primeiros anos da adesão à postura existencialista são como que calibrados pela sua elaboração - também ela, original - dessa psicanálise existencial em que o crítico acrescenta ao seu escopo de análise, além da obra do autor e do texto em seu contexto histórico e cultural, a identificação, na tecitura da escritura, da marca do que interessa, motiva e, até, obsedia o escritor. Suas tautologias e repetições (a "escritura da insistência") revelam, então, o seu desejo de escrever. E sua escritura "se constitui em reflexo total do sentido do ser; ela faz aflorar, na trama do seu discurso, o sentido simbólico que assombra perpetuamente a existência do escritor" (DOUBROVSKY 1966, p.215).

Esse vai-e-vem entre os ensaios $(1963,1966,1980,1988)$ mostra bem o fluxo contínuo e coerente do interesse e da própria obsessão de Doubrovsky, dentro de sua abordagem crítica e produção teórica original e pessoal. Essa mesma constância se reconhece no estilo fragmentário dos escritos autoficcionais: o "discurso quebrado".

O "discurso quebrado", por um lado, evoca o capítulo "O texto quebrado" de $S / Z$ (em que Barthes fala da análise dos códigos e vozes que coexistem em Sarrazine, 1970), além de anunciar um futuro título autoficcional, Le Livre brisé (que será editado sete anos depois da primeira publicação de Un Amour de soi, elevando a outro patamar a questão do tempo discursivo - outra questão interessante na obra de Doubrovsky, mas que não cabe desenvolver aqui). A insistência sobre a ideia de "quebrado" revela a sua importância para o autor, e reverbera, ao longo da obra, sua função-chave: servir de código pessoal para a virtualidade metatextual de sua escritura.

Por outro lado, ele atende à necessidade, explicitada na apresentação de Un Amour de soi, de refletir a "civilização decomposta": linguagem como 
espelho de uma "desconstrução". Assim como a verdade, que, na autoficção, não é algo que se encontra, mas que se constrói, por ser o resultado ficcional de um processo de escritura, o sentido do texto permanece como instância fugidia, sempre a ser (re)construído, na medida em que o estilo fragmentário convida o leitor a penetrar nos meandros do discurso, na tentativa de refazer um itinerário, um roteiro de viagem pelos diversos momentos passados. $\mathrm{E}$ a ordem aparentemente "desconstruída" tem afinidade com o "stream of consciousness" - linguagem do inconsciente, tema da psicanálise, que fundamenta a autoficção.

Essa "torrente" de linguagem será tanto material de trabalho do romancista quanto do crítico Serge Doubrovsky. O personagem Serge diz:

Gosto de ler, escrever ainda mais, diante da minha máquina, vadiagem impactante entre as palavras, itinerários crepitantes de termos tobogan vertiginoso através de frases, quando se desliza, sem poder se agarrar à ladeira ensaboada das sílabas. $(A S, \mathrm{p} .83)$

Estou começando a terceira versão do meu romance (...). Fluindo pelas profundezas das palavras, abismado no fluxo das frases. ( $A S$, p.342)

A repetição de termos e ideias vai formar, também no texto de Doubrovsky, uma rede significante, calcada em deslocamentos de sentidos em cada uma das várias cadeias identificáveis ao longo do texto - que funcionam como fios condutores em um labirinto de signos disseminados, gerando novos sentidos. Esses fios, de acordo com Doubrovsky, possuem

[...] o poder de indução, de orientação, para usar o termo proustiano (...) que certos significantes possuem para o sujeito da escritura e que organizam o seu texto, reconhecíveis (...) por certas asperidades ou nodosidades da textura (...) [tornadas] transgressão com relação ao (bom) estilo (...) Ceder a iniciativa às palavras (...) Esse abrasão elementar de fonemas, puxando/tecendo [tirant/tissant $]$ sentido, ao acaso das repetições inesperadas, eis o que lhe dá corpo (e alma). (1988: 56-57)

A preocupação fonética de Doubrovsky acaba sendo, também, uma citação de Proust, que faz da frase uma experiência fenomenológica, numa minuciosa arquitetura de palavras (especialmente os nomes próprios) tornado-as signos de reminicências: através de suas sonoridades (ou musicalidade), evocando nostalgicamente, encantoando, tempos perdidos (numa mise en abyme entre significado e significante). Proust insiste sobre certos sons e atribui-lhes sentidos e imagens - insistência ou repetição que alguns críticos de sua época 
entenderam como signo do mau estilo. E escolhe, dentre as palavras, aquelas que retratam os grupos sociais a que pertencem os personagens, apropriando-se de suas linguagens e esquadrinhando um verdadeiro mapeamento das diferenças sócio-culturais. "Proust escreve mal" afirma Doubrovsky (idem, p.56), como ele próprio: não porque "as incorreções pululem" (como muitos contemporâneos disseram sobre o texto de Proust), mas na medida em que ambos privilegiam a repetição fonética, em flagrante transgressão a fórmulas estilísticas convencionais, enquanto matêm-se fiéis à necessidade de expressar, cada qual, o seu tempo.

E, justamente, ao infringir as normas do bom estilo, Doubrovsky acaba revelando-se um virtuoso discípulo de Proust. Eis o que escreveu o escritor, em carta à amiga Mme Straus, em 6 de novembro de 1908, sobre uma crítica feita por um conhecido comum, que defende o uso correto e convencional da língua:

As únicas pessoas que defendem a língua francesa (como o exército, durante o Caso Dreyfus) são as que "a atacam". Essa ideia, de que existe uma língua francesa, independentemente dos escritores, e de que nós a protegemos, é inaudita. Cada escritor é obrigado a fazer a própria língua, assim como cada violonista é obrigado da fazer o seu "som" (...) Não estou dizendo que gosto dos escritores originais que escrevem mal. Prefiro - e isso seria uma fraqueza - os que escrevem bem. Mas eles só começam a escrever bem na condição de serem originais, de fazerem, eles mesmos, a sua língua (...) A única maneira de defender a língua é atacando-a, sim, Madame Straus! Porque sua unidade é feita tão somente de contrários neutralizados, de uma imobilidade aparente que oculta uma vida vertiginosa perpétua. Pois nós só nos firmamos, só fazemos bela figura ao lado dos escritores do passado se tivermos buscado escrever de outra maneira. E quando queremos defender a língua francesa, na realidade, escrevemos de maneira totalmente contrária ao francês clássico (...). Infelizmente, Madame Straus, as certezas não existem, sequer as gramaticais. Melhor assim. Porque a própria forma gramatical pode ser bela, e só pode ser belo o que contém a marca de nossa escolha, de nosso gosto, de nossa incerteza, de nosso desejo, e de nossa fraqueza (...) [O seu amigo] volta-se para trás, [e] a diversidade dos planos deveria multiplicar, para ele, a beleza das perspectivas. Mas o dogma gramatical o mantém acorrentado. (in KOLB, 1981, p.276-278)

Moderníssimo. Atualíssimo. Proust compara o uso da língua pelo escritor ao uso das notas pelo músico, e defende, não a aplicação ortodoxa da gramática, mas a manipulação criativa e original da língua, jogando com a dinâmica que lhe é inerente, acionando sua "perpétua", atemporal, "vida 
vertiginosa". Como no "tobogan" de Doubrovsky, essa vertigem é resultado do enfrentamento pessoal "de nosso gosto, de nossa incerteza, de nosso desejo, e de nossa fraqueza". Ei-lo, explicitado, também aqui, o "desejo" do escritor, como fundamento da escritura. Proust, na verdade, vai mais longe: como fundamento do belo. Doubrovsky não fala do belo, mas da literatura historicamente e culturamente ancorada em seu tempo; e de si mesmo, como produto e observador inevitável desse tempo.

Proust, em seu olhar ideal retrospectivo, crê na produtividade da diversidade das maneiras de ver; Doubrovsky, em seu olhar ideal fragmentário, investe na produtividade da diversidade das maneiras de se ver. Em ambos os casos, é exigido do leitor a capacidade de ultrapassar o texto, de superá-lo, e, induzido pelo próprio caráter transgressor do livro, de ir além, para algum lugar que se encontra fora da obra, de sua economia e de sua gramática. ${ }^{4}$ Como o observador de uma instalação, o leitor ideal desses escritores-críticos-teóricos é convocado a embarcar na aventura do próprio gosto, da própria incerteza, do próprio desejo e da própria fraqueza.

\section{ABSTRACT}

One can associate Serge Doubrovsky's novel to the idea of installation due to the author's general intent (as he explains in many of his essays) of elaborating his "autofiction": he wishes to invoke the reader's sensitivity through means that bypass the mere cultivated reading. He intends, through his "consonantic writing", to make direct contact with other arts, especially music and visual arts, since he bases it on phonetic properties, which, according to him, generate creativity and productivity in the semantic field. The author also intends to communicate directly with the reader's affectivity and affective impulses, through his "existential psychoanalysis" and his writing "to the unconscious". The "broken discourse" is his main instrument to achieve this goal. This proposition, apparently innovative, may be traced back to one of this favorite themes of study: Marcel Proust's work.

KEYWORDS: Doubrovsky, autofiction, broken discourse, Proust 


\section{REFERÊNCIAS}

BARTHES, Roland. O Prazer do texto (Tradução de Maria Margarida Barahona). Lisboa: Edições 70, 1983.

DOUBROVSKY, Serge. Autobiographiques: de Corneille à Sartre. Paris: PUF, 1988.

. Corneille et la dialectique du héros. Paris: Gallimard, 1963.

. Faire catleya. In: Poétique n³7. Paris: Seuil, 1979, p.111-125.

. La Place de la madeleine, écriture et fantasme chez Proust. Paris: Mercure de France, 1974.

1966.

. Pourquoi la nouvelle critique. Critique et objectivité. Paris: Mercure de France,

. Parcours critique. Paris: Galilée, 1980.

. Un Amour de soi. Paris: Hachette, 1990 (1982).

GRELL, Isabelle et alii. Serge Doubrovsky: comment le monstre devint fils. http://www.everyoneweb.com/doubrovskymanuscrit.com [2014]

KOLB, Philip. Marcel Proust. Correspondance. Tomo VIII (1908). Paris: Plon, 1981, p.276-279.

MALLARMÉ, Stéphane. Quant au livre. In: Oeuvres complètes. Paris: Gallimard, 1945, p.369-387.

\section{NOTAS}

${ }^{1}$ Serão, ao todo, sete títulos autoficcionais, independentes mas correlatos, às vezes reciprocamente referentes: Fils (1977), Un Amour de soi (1982), La vie l'instant (1985), Le livre brisé (1989), L'Après-vivre (1994), Laissé pour conte (1999), e Un homme de passage (2011), além de Le Monstre (2014).

${ }^{2}$ Uma tradução meramente ilustrativa seria: "BURBURINHO / na balbúrdia avanço / convidados aglutinados / em grupos gesticulantes / ensurdecido pela algazarra das vozes dos copos / - Sim, ela queria te conhecer. Ela me pediu / - Mesmo? / - Pediu. Vem, vou te apresentar. / festim universitário malta de colegas / através da massa eriçada de tilintares nas pontas dos dedos agitados / sopro dos risos que gorgeiam enquanto passos arrulham gargalham roucos latidos das goelas sábias avinhadas".

${ }^{3}$ Que pode ser traduzido como "salão turbilhonte de ecos, barafunda engravatada algazarra eloquente de erudição (...) mal entrei ela me arrasta com grande estardalhaço/ 
O “DISCURSO QUEBRADO” DE SERGE DOUBROVSKY: ESCRITURA COMO INSTALAÇÃO?

aos empurrões e aos berros [dois sentidos possíveis] pela multidão/combate corpo a corpo [dois sentidos possíveis]".

${ }^{4}$ Analiso o leitor e a leitura na obra de Proust no terceiro artigo que consta no resumo sobre o autor, entre outros.

Recebido em: 22 de maio de 2015

Aceito em: 05 de setembro de 2015 